Research Article

\title{
Estimation of Extreme Cable Forces of Cable-Stayed Bridges Based on Monitoring Data and Random Vehicle Models
}

\author{
Yuan Ren, ${ }^{1}$ Zhiyuan Zhu, ${ }^{1,2}$ Ziyuan Fan ${ }^{10},{ }^{1}$ and Qiao Huang ${ }^{1}$ \\ ${ }^{1}$ School of Transportation, Southeast University, Nanjing 211189, China \\ ${ }^{2}$ Jiangsu Yangtze Highway Bridge Co., Ltd., Nanjing 210004, China \\ Correspondence should be addressed to Ziyuan Fan; fanzy1216@163.com
}

Received 29 July 2020; Revised 31 March 2021; Accepted 6 April 2021; Published 14 April 2021

Academic Editor: Tingting Zhang

Copyright (c) 2021 Yuan Ren et al. This is an open access article distributed under the Creative Commons Attribution License, which permits unrestricted use, distribution, and reproduction in any medium, provided the original work is properly cited.

For long-span cable-stayed bridges, cables serve as one of the most important components to guarantee structural integrity. Forces of stay cables indicate not only the performance of cables themselves but also the overall condition of bridges. In order to help stakeholders to make maintenance decisions, an extreme cable force estimation method was proposed based on cable force measurements and traffic data from the weighing system. First, raw monitoring data were preprocessed based on a median filtering to obtain usable cable force signals. The multiresolution wavelet method was used to extract traffic-induced force component from mixed signals. Then, a Monte Carlo-based random vehicle model was developed using traffic data from the weighing system. Based on field temperature measurements and simulation of traffic-induced effects, extreme cable forces with respect to vehicle loads and temperature effects were predicted by extreme value theory. The Generalized Pareto Distribution (GPD) was adopted to establish the probability distribution models of the daily maximum cable force. Then, the extreme value within a return period of 100 years was determined and compared with the design loading demand. Finally, the effectiveness of the proposed method was validated through a cable-stayed bridge in China. As a result, the low-frequency varying component of cable force response had positive correlation with environmental temperatures, and the extreme value of the predicted cable force under prospective traffic volumes was within limit interval value according to the design code. The conclusions can be utilized by bridge owners to make maintenance decisions.

\section{Introduction}

With rapid growth of infrastructure investment in recent years, more and more long-span cable-stayed bridges have been constructed over rivers and valleys [1]. Meanwhile, traffic volumes of bridges have increased significantly compared to those when bridges were initially opened to public traffics, especially in some emerging countries [2-4]. For instance, China's annual growth rate of freight traffic volume approached 6\% in 2018 [5], which was a critical parameter for evaluation of structural performances. Structural responses might exceed the designed ones in the following several decades owing to the pressure of rapid increase in traffic volumes [6]. This phenomenon will inevitably impact operational and structural safety of long-span cable-stayed bridges. In this regard, measures should be taken to investigate the actual responses of bridge components (stay cables, towers, girder, etc.). Moreover, further prediction is necessary based on existing information and extreme value estimation methods. Nowadays, structural health monitoring (SHM) systems have been installed in plenty of long-span cablestayed bridges [7-9]. With the assistance of SHM systems that consist of various sensors, real-time responses of cable-stayed bridges under different actions can be recorded, so a large amount of monitoring data has been accumulated for further discussion. It is possible to take advantages of these monitoring data to investigate the actual loading effect and to evaluate and predict the performance of structural components [10-12].

For cable-stayed bridges, the stay cable is regarded as one of the most important components to ensure the allowable displacement and distribution of bending 
moments along the bridge deck with prestressing force [13]. Sensors installed in cables are used to collect real-time signals in a SHM system of cable-stayed bridges. Then, the cable forces can be obtained directly or can be calculated from indirect measurements such as frequency or acceleration [14]. It is primary to analyze the characteristics of recorded cable force signals under actual loading conditions. Signals induced by temperature actions and vehicle loadings are two main ingredients in the mixed signal, namely, slow-varying ingredient and dynamic ingredient, respectively [15-17]. To extract different components, blind separation methods are usually adopted [18]. Xu et al. [19] used a multiresolution wavelet-based method to separate thermal effects from bridge responses based on the distinguished frequency bandwidths. A practical multivariate linear-based model was also presented to simulate and separate thermal effects from the cable-stayed bridge response [20]. Kromanis and Kripakaran [21] suggested novel data-driven methods referred to as Regression-Based Thermal Response Prediction and Traffic-Induced Response Prediction to predict thermal and vehicular response. The proposed methods were evaluated by experimental data collected from a laboratory truss. Zhou and Sun [22] established a sound understanding of thermal response in cable-stayed bridges and found that the thermal response of cables was mainly determined by environmental temperature. In addition, thermal response of cables subject to fire was also studied $[23,24]$.

To predict the performance of cables, the random vehicle model should be established to simulate traffic-induced cable force responses under prospective traffic volumes. Previously, the passing vehicles were only tracked and identified by monitoring camera system on bridges [25]. Now, the weigh-in-motion (WIM) system is widely used in long-span bridges for ascertaining vehicle parameters, including total weight, axle distance, speed, and driving lane [26]. In this field, Ma et al. [27] obtained basic vehicle information based on traffic data analysis, and the statistical distribution functions of gross vehicle weight under different loading conditions and wheelbase for each type of vehicle were also analyzed to develop the vehicle model. Wang et al. [28] proposed a vehicle model for long-span bridges in the framework of Eurocode Load Model 1, in which multiple lane factors and impact factors were taken into account. Zhou et al. [29] used micro- and macrosimulation with different load model varieties of traffic loading in different bridge regions to propose an efficient multiscale traffic modelling approach. Guo et al. [30] developed a vehicle load model based on weigh-in-motion data, which considered the uncertainties associated with the number of axles, axle weights, axle spacing, and transversal position of vehicles. Then, the model was used to evaluate the fatigue reliability of steel bridge details. It is also a significant work to forecast future traffic volumes based on current traffic volumes as both seasonality and growth trend can be included [31]. However, there are rare studies published in evaluating prospective performance of cables combining monitoring data with extreme value calculated from random vehicle model [32].
In this paper, the cable forces of cable-stayed bridges were discussed and the extreme value was predicted based on monitoring data and the developed random vehicle model. First, a median-filtering-based preprocessing was conducted to obtain usable cable force measurements. The multiresolution wavelet method was used to extract trafficinduced force. Meanwhile, the Monte Carlo based random vehicle model was developed using traffic data from bridge weighing system. Then, the extreme cable forces with respect to vehicle loads and temperature effects for the return period of 100 years were predicted by applying the Generalized Pareto Distribution (GPD) model. Finally, the reliability of the proposed method was validated by a case study of a longspan cable-stayed bridge, the third Nanjing Yangtze River Bridge in China.

\section{Methodology}

At present, monitoring systems are widely installed in longspan cable-stayed bridges. The monitoring data, including cable force measurements from SHM system and traffic data from weighing system, can achieve continuous collection. However, further investigation is still needed to obtain valuable information from mass data. Considering the probable performance of stay cables within the return period (which can be regarded as an approximate frequency of occurrence [33]), an analysis and estimation method was developed based on current monitoring data and the average daily traffic, as shown in Figure 1. Firstly, the raw data was preprocessed. Then, effectiveness of the developed random vehicle model was verified by the separated vehicle-induced cable forces. Finally, the GPD model was adopted to predict extreme values of cable forces in the future.

2.1. Processing for Monitoring Data. At present, the recorded cable force data by SHM systems includes direct and indirect measurements. Compared with the common vibrationbased measurements, the direct force measurements help to know the operational condition conveniently. The influence of conversion error was also eliminated to ensure data accuracy. However, direct measuring methods skip the transforming procedure such as fast Fourier transform (FFT), which can reduce signal noise simultaneously. Therefore, it is necessary to perform preprocessing to eliminate the influence of data noise before analyzing the direct cable force measurements. Figure 2(a) shows the typical cable force measurements collected by sensors. It indicates that the signals are considerably affected by saltand-pepper noise, which is caused by the uncertainty of sensor measurements itself and transmission channels as well as the decoding process. In this paper, the median filtering was used to deal with the raw signals, and the output of filter is denoted as follows:

$$
y(i)=\operatorname{Med}[x(i-N), \ldots, x(i), \ldots, x(i+N)]
$$

where $y(i)$ deontes the output signals, Med is the filtering function, $x(i)$ is the input signals, and $N$ is the selection number to ensure the window width of $2 N+1$. The basic 


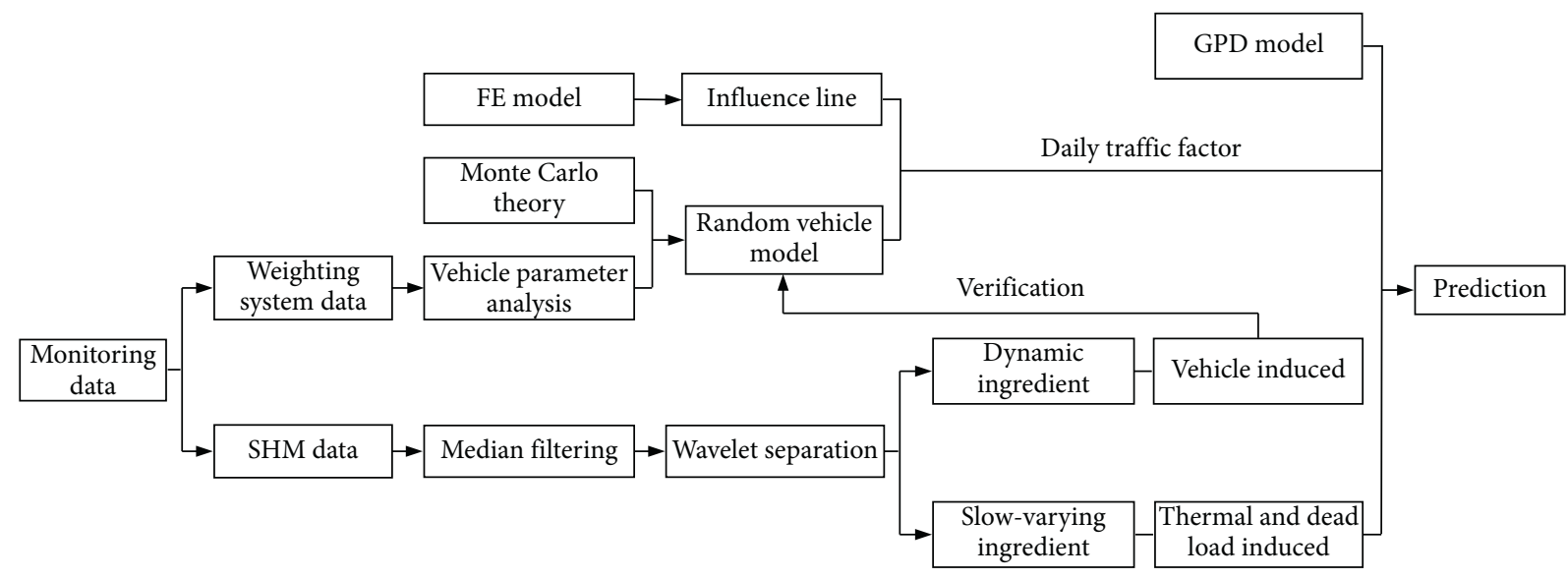

FIGURE 1: The flowchart of the method.

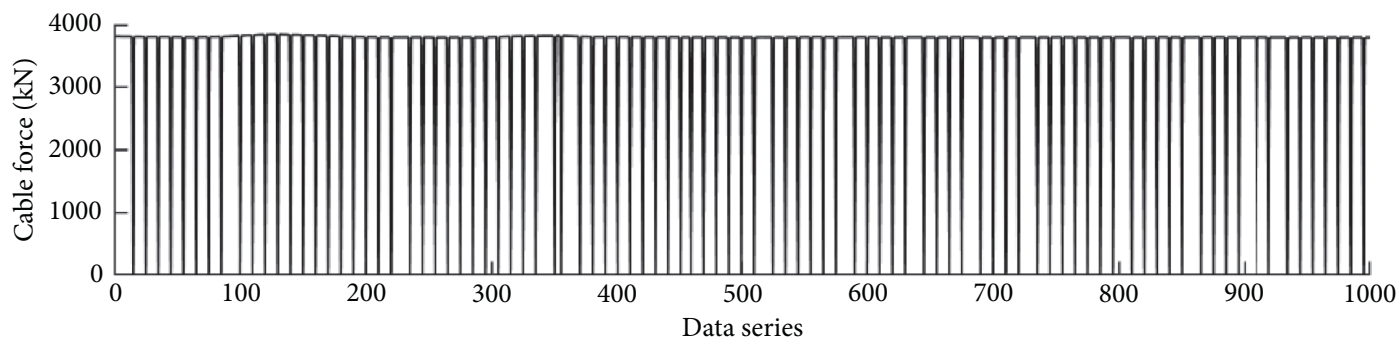

(a)

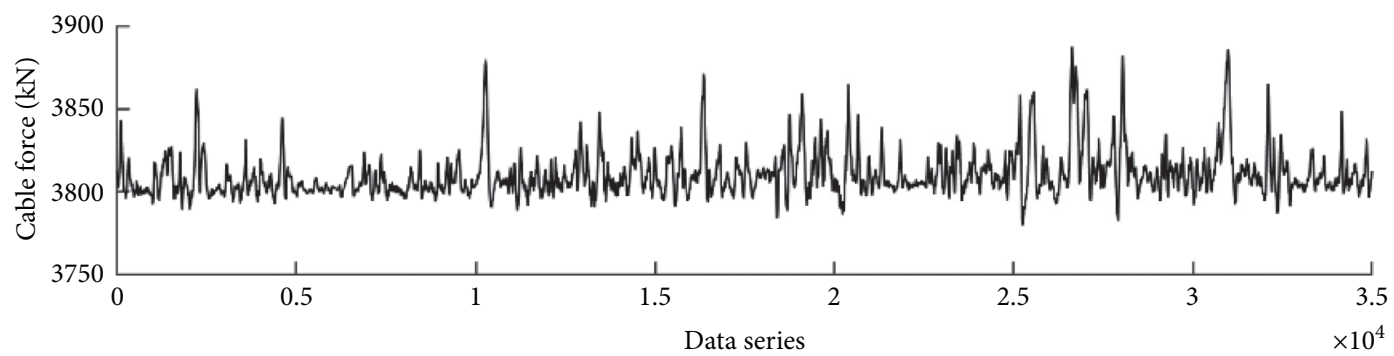

(b)

Figure 2: Preprocessing for monitoring data: (a) the raw signals; (b) the filtered signals.

theory of median filtering is to replace the value of a certain point in the data series with the median value of the adjacent several points. For instance, Figure 2(b) shows the results of median filtering with a window width of 5 . Thus, the signals were filtered without the effects of noise.

To simplify, the monitoring cable forces in bridge service period are considered as the linear superposition of temperature effect and dead load-induced force and vehicle load-induced force, corresponding to slow-varying ingredient and dynamic ingredient in signal, respectively. Compared with traffic load, the wind effect to cable force is ignored in this paper for it does not significantly influence the results, which was also validated by existing research $[34,35]$. The signal is denoted as follows:

$$
\begin{aligned}
x(t) & =F_{T}(t)+F_{L}(t), \\
F_{T}(t) & =k \times T(t)+c,
\end{aligned}
$$

where $x(t)$ is the monitoring cable force signal, $F_{T}(t)$ is the total cable force induced by environmental temperature effect and dead load, $F_{L}(t)$ is the cable force induced by vehicle load, $T(t)$ denotes the environmental temperature measurements, and $k$ and $c$ are constant parameters.

To separate signals of aforementioned two ingredients, the multiresolution wavelet method based on distinguished frequency bandwidths is adopted [19]. The core idea of wavelet method is to use a finite length or fast decay wave to reconstruct signals. A time-domain signal $f(t)$ can be 
described as the convolution of a wavelet coefficient $W_{f}$ and a wavelet function $\psi(t)$. After mathematical transformations, the wavelet function $\psi(t)$ can be expressed as follows:

$$
\psi_{a, b}(t)=|a|^{-1 / 2} \psi\left(\frac{t-b}{a}\right),
$$

where $a$ and $b$ are stretch parameter and translation parameters. The wavelet coefficient $W_{f}$ explains the similarity between signals $f(t)$ and wavelet function $\psi(t)$, which is

$$
W_{f}=|a|^{-1 / 2} \int_{R} f(t) \psi\left(\frac{t-b}{a}\right) \mathrm{d} t .
$$

The multiresolution wavelet method transforms the signals to approximation and detail coefficients that depict the frequency distribution in the time and frequency domains, as shown in Figure 3. Ai denotes the $i^{\text {th }}$ term of approximation, while Di denotes the $i^{\text {th }}$ term of detail. Thus, the original signals can be separated. For instance, Figure 4 shows the one-day monitoring cable force data for a typical stay cable with a sampling frequency of $1 \mathrm{~Hz}$. The wavelet separation was conducted with Db12 wavelet to obtain the slow-varying ingredient with low frequency, namely, the total cable force induced by environmental temperature and dead load. The rest was regarded as the high-frequency ingredient, that is, the total cable force induced by vehicle load.

2.2. Establishment of the Random Vehicle Model. Similar to other codes, the Chinese codes mention that the vehicle load should be modified based on the actual situation during the assessment [36]. The mentioned modified factors that significantly influence the extreme value of vehicle-induced cable forces include the annual average daily traffic (AADT) and the proportion of heavy vehicles. In the early operational period of bridges, the traffic volume gradually increased but usually would not reach saturation. Thus, the accumulated data in early period should not be directly used to predict the extreme cable forces in the future. Therefore, the traffic growth is often considered a critical factor of the future traffic effect [37]. In this paper, a random vehicle model was developed to predict the extreme value of vehicle loads with prospective traffic volume. To establish the random vehicle model, the major vehicles in operation were divided into different types according to axle parameters based on the weighing data and monitoring video. The maximum likelihood estimation and expectation maximization (EM) algorithm were used to build the probability models of major vehicle parameters, such as vehicle type, total weight, axle weight, arrival time, wheelbase, driving lane, and speed.

Then, the establishment procedure for dynamic random vehicle model was developed in several stages, as shown in Figure 5. Firstly, traffic volume and simulation duration were determined. Vehicle arrival time and number were also generated via Poisson processing. Then, the probability models of vehicle parameters were utilized to develop a Monte Carlo based vehicle database, which was regarded as inputs of vehicle-following program, hence the dynamic traffic flow. Finally, the random vehicle model was acted on structural influence lines to calculate the time history of vehicle-induced responses.

2.3. Extreme Value Analysis and Estimation. To realize extreme cable force estimation in the field of statistics for the return period, it is required to estimate the extreme cable forces from current records [38]. As a supplement to the normal distribution, the extreme value method was proposed to predict confidence limits on extreme cable forces [39]. In view of the complicacy of the signals, two preprocessed ingredients were analyzed, respectively. Assume that these two ingredients data series (slow-varying ingredient is analyzed seasonally) were stationary, independent, and in accord with GPD model. The common methods to obtain the extreme value of stationary data series include interval maximum value and peaks over threshold (POT). Due to the insufficiency of the accumulated data, the assumptions of interval maximum model were difficult to meet. Therefore, the POT model described by the GPD was eventually utilized to estimate the return level of cable force $[40,41]$. For a stationary series $X_{1}, \ldots, X_{n}, A_{i, n}$ is denoted as

$$
A_{i, n}=\left\{X_{i}>u_{n}, X_{i+1} \leq u_{n}, \cdots, X_{i+r} \leq u_{n}\right\},
$$

where $u_{n}$ is the selected threshold, and $A_{i, n}$ is a subsample indicating that $X_{i}$ exceeds $u_{n}$. Then, at least subsequent $r$ consecutive data are lower than $u_{n}$, where $n$ is the total amount of data. Based on the GPD model, the POT extreme value analysis and estimation for stationary data series mainly involve the four following:

(i) Step 1: determination of subsample

Based on abundant monitoring data, subsample $A_{i, n}$ corresponding to the certain threshold $u_{n}$ and number $r$ should be determined. To select the suitable threshold $u_{n}$, the average excess function $e(u)$ of the excess quantity $u$ is computed. The threshold $u_{n}$ can be determined by focusing on the slope change characteristics of $e(u)$. The turning point of $e(u)$ can be used as the threshold.

(ii) Step 2: maximum excess quantity calculation Then, the maximum excess quantity for each subsample $A_{i, n}$ is obtained through calculating deviations of series data and the selected threshold $u_{n}$.

(iii) Step 3: GPD fitting and parameter estimation Assuming that it is independent, each maximum excess quantity can be fitted by the GPD model with 2 parameters, which can be expressed as follows:

$$
\bar{G}(x, \sigma, \xi)= \begin{cases}{\left[1+\xi\left(\frac{x}{\sigma}\right)\right]^{-1 / \xi},} & \xi \neq 0, \\ e^{-x / \sigma}, & \xi=0,\end{cases}
$$

where $\xi$ is the shape parameter and $\sigma$ is the scale parameter. The variable $x \in D(\sigma, \xi)$ can be denoted as follows: 


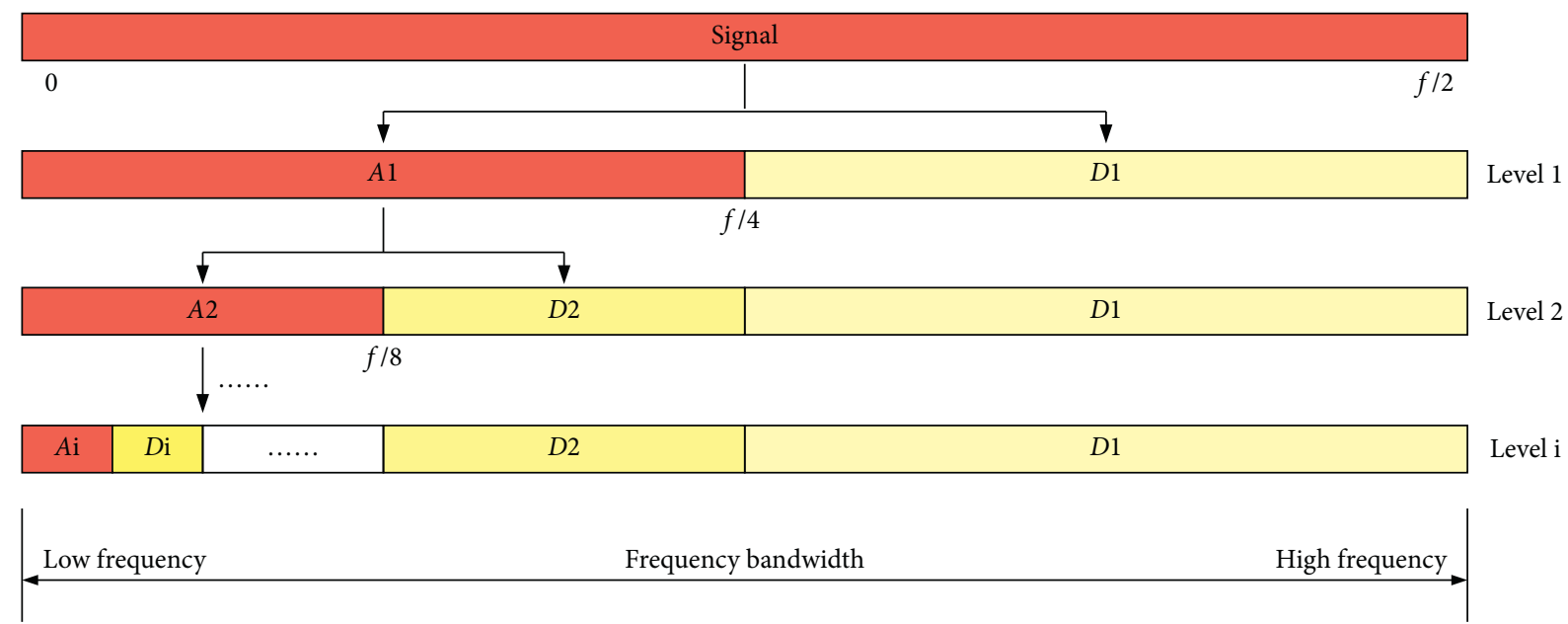

FIGURE 3: The schematic representation of wavelet method.

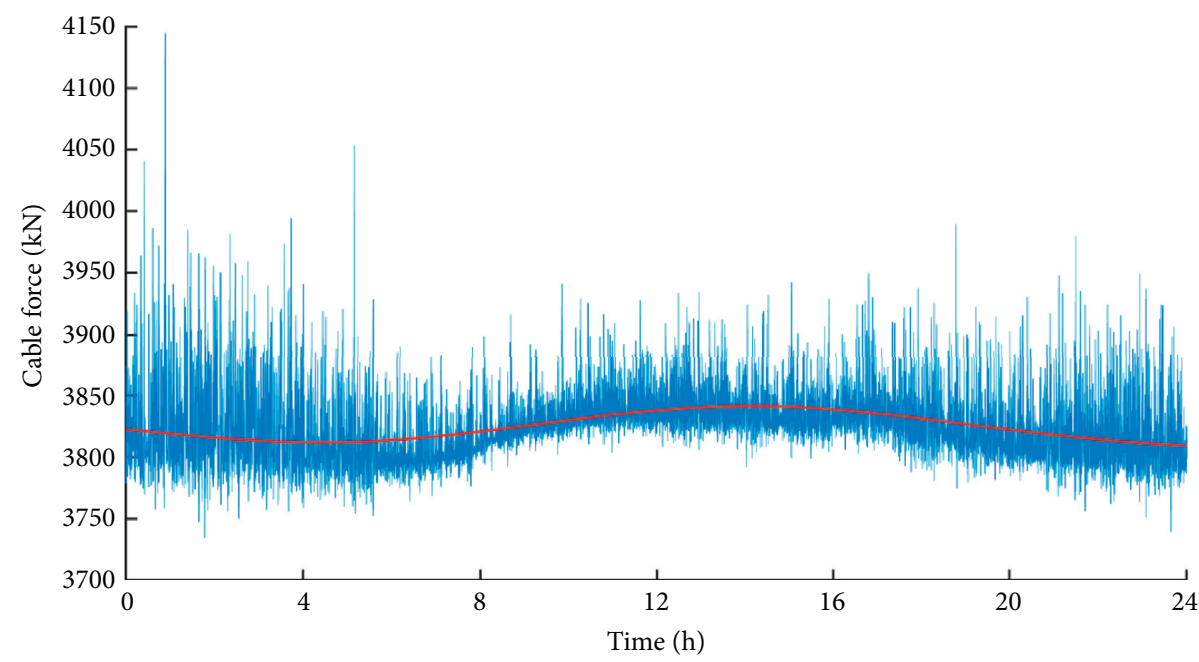

$$
\begin{aligned}
& \text { - Original signal } \\
& \text { — Slow-varying ingredient } \\
& D(\sigma, \xi)= \begin{cases}{[0, \infty),} & \xi \geq 0, \\
{\left[0, \frac{-\sigma}{\xi}\right],} & \xi<0 .\end{cases}
\end{aligned}
$$

FIgURE 4: Separation results of signals.

The GPD fitting is conducted with data to estimate the shape parameter $\widehat{\xi}$ and the scale parameter $\widehat{\sigma}$.

(iv) Step 4: extreme value estimation

With estimated parameters, the POT model described by the GPD is established to estimate maximum excess quantity. Therefore, the GPD-based extreme value of data series $\left\{X_{i}\right\}$ can be calculated as

$$
x_{1-(1 / p)}=u_{n}+\frac{\widehat{\sigma}}{\widehat{\xi}}\left[\left(\frac{K_{u}}{n} \times p\right)^{\widehat{\xi}}-1\right] \text {, }
$$

where $p$ is return level, $K_{u}$ is the number of subsamples that exceed threshold $u_{n}$, and $n$ is the amount of data. $p$ can be determineded considering the local code. Therefore, the extreme value of temperature-related and vehicle-induced cable force can be obtained, respectively.

\section{Case Study}

The monitoring data in this paper were collected from an SHM system and a weighing system on a highway cablestayed bridge crossing Yangtze River in Nanjing, China. Several typical cables were analyzed to select the critical position. Usually, cables designed with maximum force or the longest length were emphatically studied. The traffic data from weighing system was used as a probabilistic database for random simulation. In addition, all the sensors on the 


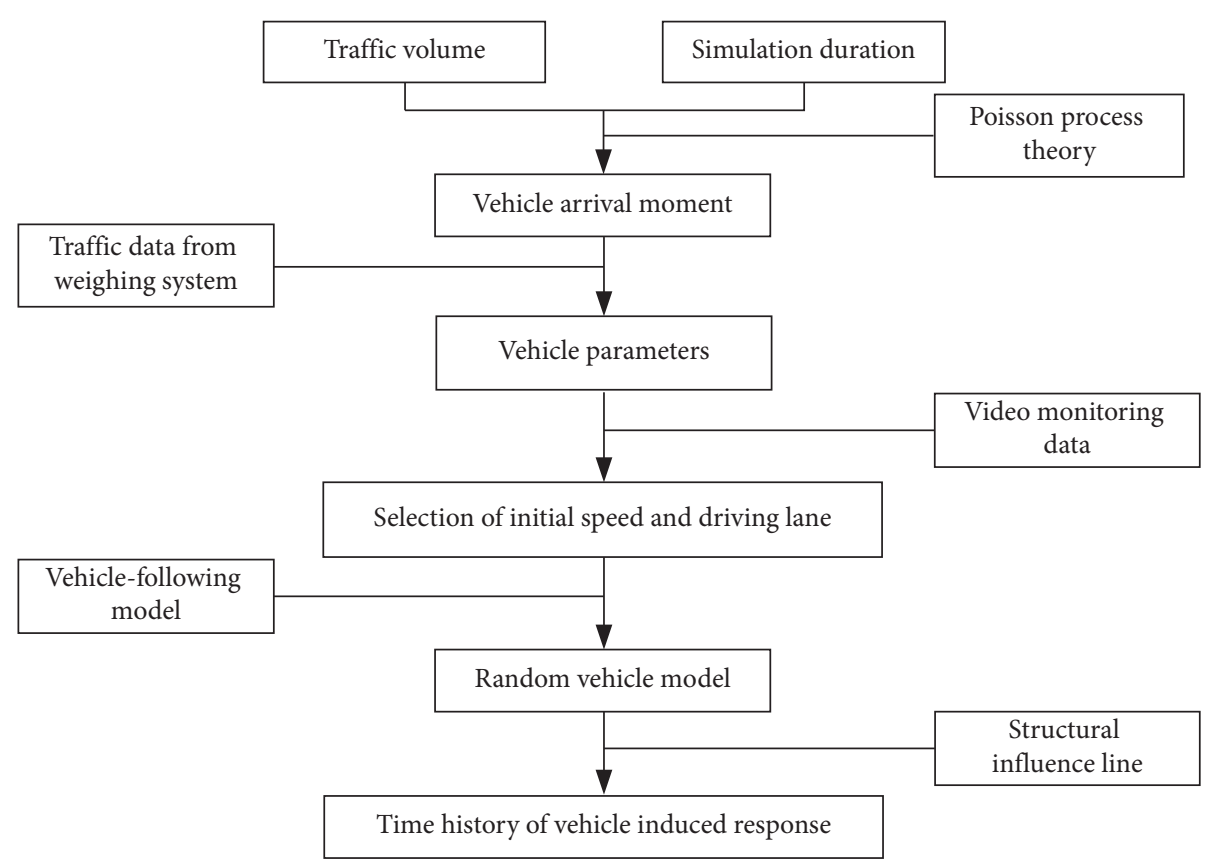

FIgURE 5: The establishment procedure of the random vehicle model.

bridge are brand new in early years so that their measurements can be utilized for analysis.

3.1. Descriptions of Bridge and Its Monitoring System. The third Nanjing Yangtze River Bridge was built in 2005, which connects Nanjing City and its Pukou District. It is a cablestayed bridge with a main span of $648 \mathrm{~m}$ and a tower height of $215 \mathrm{~m}$ and has bidirectional 6 lanes. The main girder is supported by 168 stay cables, each consisting of 109 to 241 wires with a diameter of $7 \mathrm{~mm}$. The appearance of the bridge is shown in Figure 6. A sophisticated monitoring system including an SHM system and weighing system is then devised to continually track the operational situation and structural health status. The advanced anchor load cell (ALC) sensors, which have higher precision compared to other cable force measurement approaches, are installed in the anchors of stay cables [42]. All the 168 stay cables are equipped with ALC sensors with an acquisition frequency of $10 \mathrm{~Hz}$ and a relative error of $\pm 1 \%$. Different from common acceleration sensors, the ALC received cable force measurements directly. Meanwhile, environmental temperature data can be collected by temperature sensors (TEM) around towers with R. M. YOUNG-41372 thermometers. The range of this sensor is $\left[-50^{\circ} \mathrm{C}, 50^{\circ} \mathrm{C}\right]$ with the precision of $\pm 0.3 \%$. Temperature data are also collected with an acquisition frequency of $10 \mathrm{~Hz}$.

The bridge weighing system is set at the bridge toll stations (both south and north banks). For each vehicle passing the bridge, the system will record its pass time, vehicle class, total weight, axle weight, axle distance, and driving lane. The recorded traffic data are used to establish random vehicle models combined with other parameters, such as speed and acceleration.
3.2. Estimation of Temperature Effect. For a practical cablestayed bridge, the longest cables near the mid-span are usually designed to bear the maximum force. Figure 7 shows the designed forces and length of the third Nanjing Yangtze River Bridge for all stay cables. It can be seen that cable NJ21 is the longest cable (with a length of $354.53 \mathrm{~m}$ ) of this bridge with almost the maximum force (designed as $3708 \mathrm{kN}$ ). Different from cable NA21, which is also a long cable but only in the side span, cable NJ21 directly supports the girder in the main span, so more attention has been paid to cable NJ21 by the bridge management department [43]. Hence, cable NJ21 in the third Nanjing Yangtze River Bridge was selected for a case study to validate the effectiveness of the proposed method. The structure of cable NJ21 is shown in Figure 8; it constituted 241 wires, each with a diameter of $7 \mathrm{~mm}$, so the area of total wires can be calculated as $9275 \mathrm{~mm}^{2}$. The wires are galvanized and have an ultimate strength of $1670 \mathrm{MPa}$.

In Figure 9, the total of 530 daily pieces of cable force monitoring data of cable from January 2007 to October 2009 were used and then separated into 15 layers with $\mathrm{db} 12$ wavelet basis functions. Total cable force induced by environmental temperature effect and dead load $F_{T}(t)$ was obtained, as shown in Figure 9(b). The abnormality in early 2008 was caused by a sudden snow disaster, which resulted in the significant increase of cable force monitoring data. The monitoring cable forces vary around the initial value of $3708 \mathrm{kN}$. To ensure the safety of cables and the total structure, a designed safety coefficient of more than 3 was adopted for this bridge, which accounted for the measurements being far below the limit material strength.

The obvious linear relationship can be observed between $F_{T}(t)$ and environmental temperature, as shown in Figure 10. The monitoring temperature data in the 


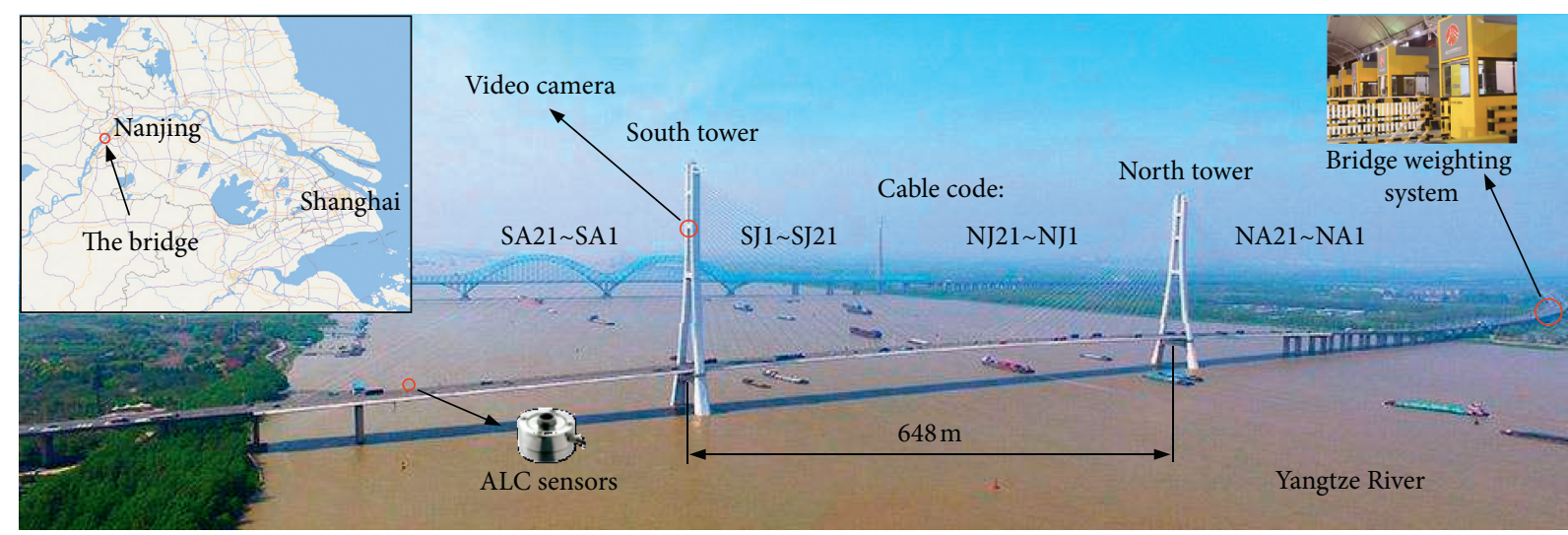

Figure 6: The third Nanjing Yangtze River Bridge.

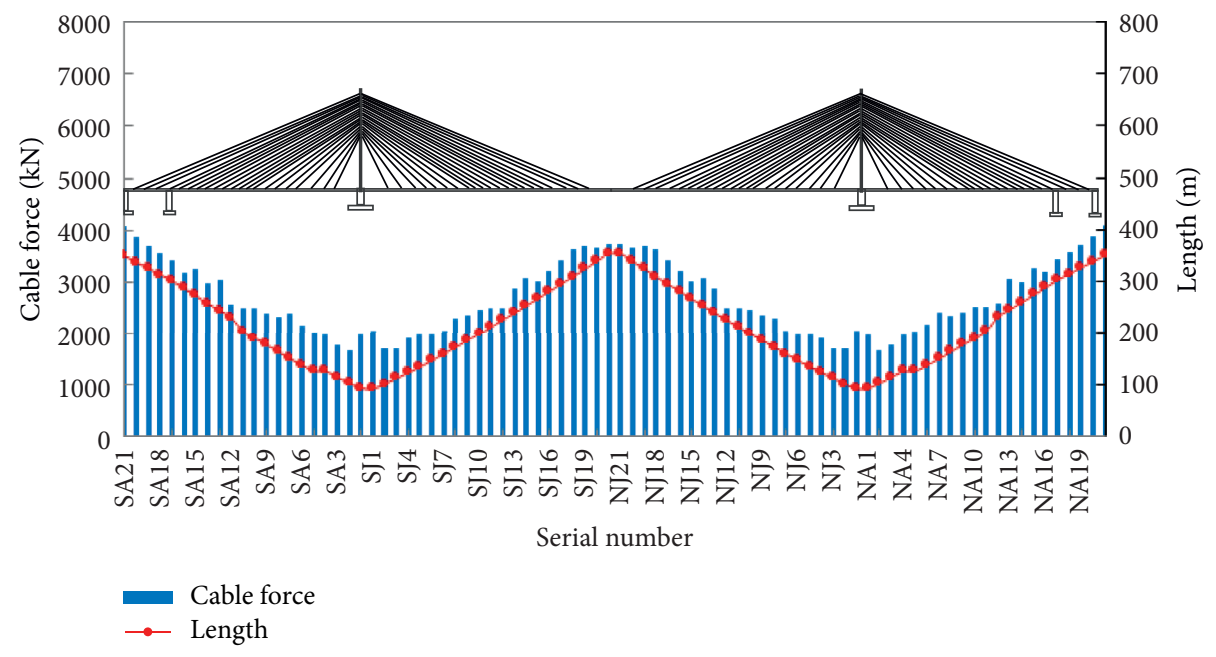

Figure 7: The designed cable forces and cable length of completed bridge.

corresponding period were also extracted to obtain the constant parameters $k$ and $c$ in equation (3). Finally, $F_{T}(t)$ can be expressed as

$$
F_{T}(t)=3.3019 \times T(t)+3651.50 \text {. }
$$

Extreme value analysis was then conducted for temperature data with the GPD model. The threshold $u_{n}$ was selected as $32^{\circ} \mathrm{C}$, while $r$ was set to 3 . Since the extreme high temperature must appear in summer, the monitoring temperature data of summer (June, July, and August) from 2006 to 2010 was utilized for extreme value analysis. The MATLAB platform was adopted to calculate the shape parameter $\hat{\xi}=-0.221$ and scale parameter $\widehat{\sigma}=3.076$. Figure 11 shows the probability density function (PDF) results from the GPD fitting.

The two parameters of the GPD processing were then substituted into equation (8) to calculate the extreme temperature $T_{e v}$ with a return period of 100 years, and the result was $45.095^{\circ} \mathrm{C}$. According to equation (9), the temperature-dead load-induced extreme value cable force $F_{\mathrm{Tev}}$ with a return period of 100 years was $3800.40 \mathrm{kN}$.
3.3. Estimation of Vehicle Effect. The weighing system data of the third Nanjing Yangtze River Bridge from January 2006 to April 2009 were extracted as a sample to analyze the vehicle characteristics. According to different vehicle axle distribution, the data were divided into 12 types, as shown in Table 1. $P$ denotes the proportion of each vehicle type within the total vehicle number. As for the vehicle axle, 2 denotes one axle and two wheels, 4 denotes one axle and four wheels, 8 denotes two axles and eight wheels, and 12 denotes three axles and twelve wheels. Thus, the parameters of random vehicle model can be determined.

Based on the associated information of vehicle types, the mixture normal distribution (MND), mixture lognormal distribution (MLD), and EM algorithm were applied to establish the statistical models of vehicle weight of different vehicle types, and the t-distribution was used to establish the statistical models of vehicle speed. The vehicle arrival time intervals were determined according to Poisson process theory. Figure 12 provides some examples of the PDF of vehicle weight (mixture lognormal distribution), vehicle speed ( $\mathrm{t}$-distribution), and arrival time interval (exponential distribution), respectively. According to the process of 


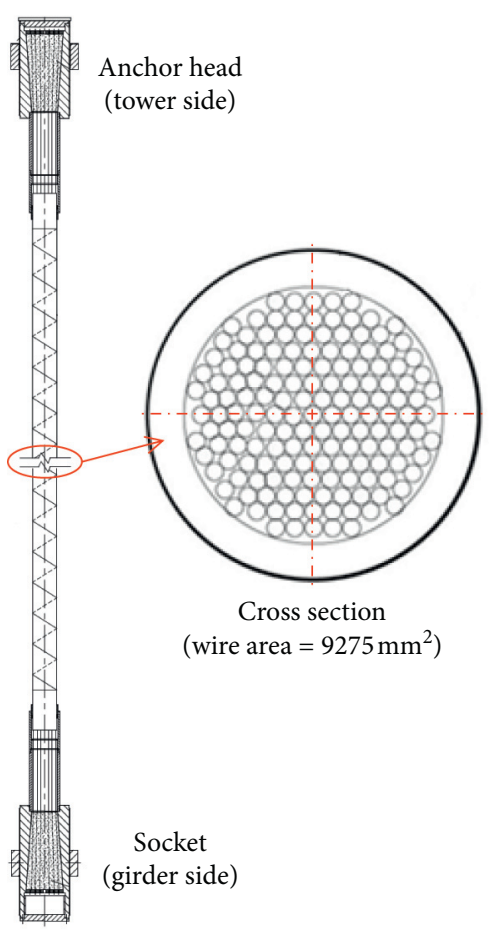

Figure 8: The structure of cable NJ21.

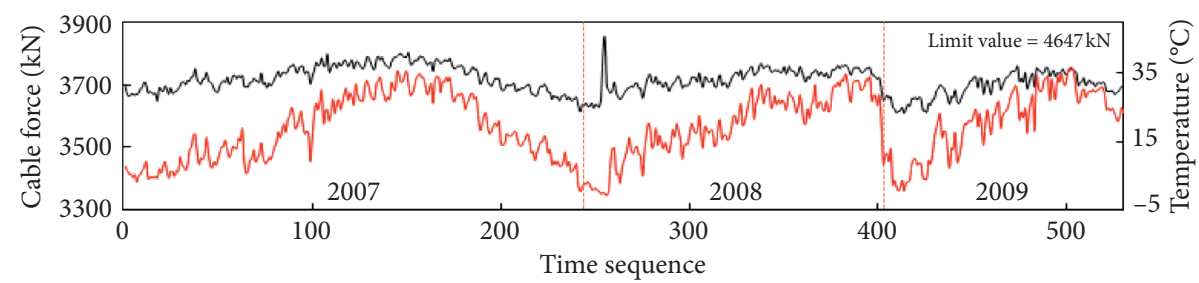

Cable force

- Temperature

(a)

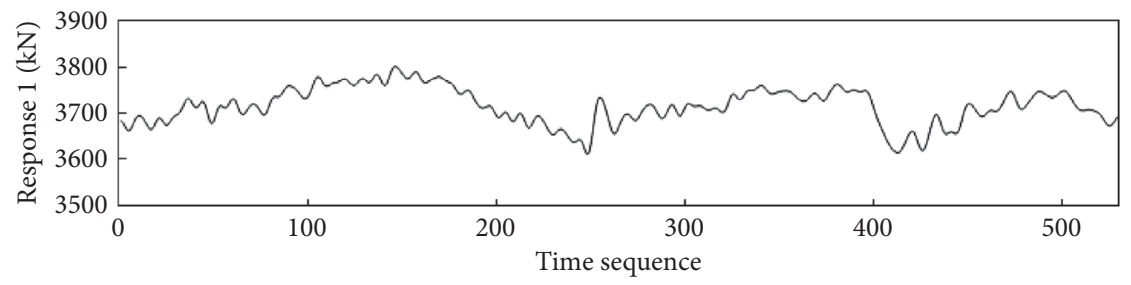

(b)

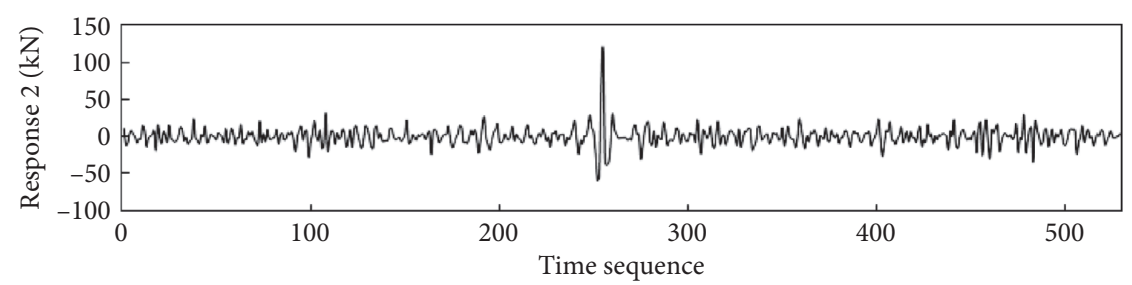

(c)

FIgURE 9: The subsignal of monitoring data after wavelet separation. 


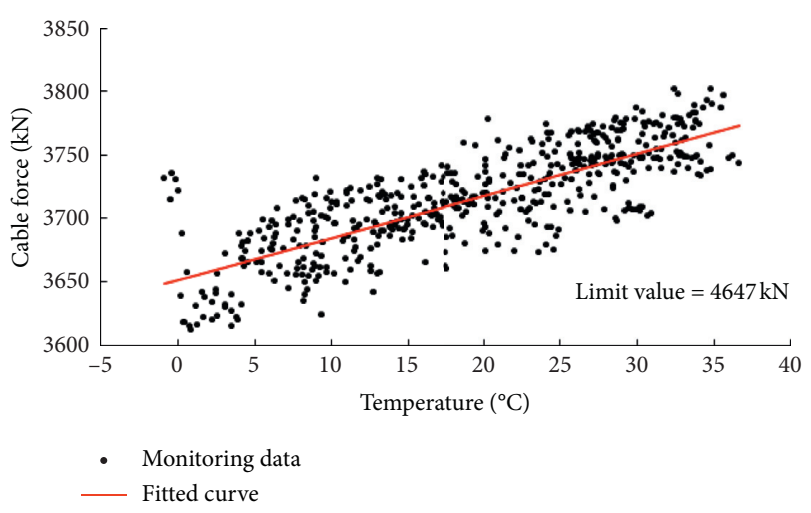

FIgURE 10: The relationship between separated cable force and temperature.

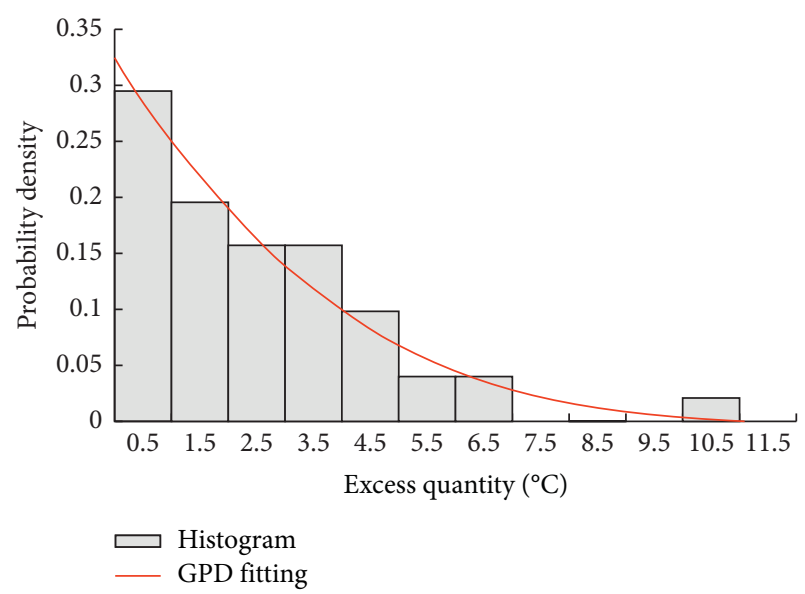

FIgURE 11: The PDF of the GPD for temperature excess quantity.

determining the parameters of random vehicle model, it is obvious that all the parameters are obtained through the analysis of vehicle data collected from the weighing system in real bridge. Then, the random vehicle model was developed with the Monte Carlo method, which can be used to simulate dynamic traffic flow for the third Nanjing Yangtze River Bridge.

In order to verify the reliability of the random vehicle model developed in this study, the simulated vehicle flow was acted on structural influence lines to calculate the time history of vehicle-induced responses, which was then compared with the monitoring cable forces. Similarly, the cable NJ21 was selected to be investigated. The cable force influence line for cable NJ21 and the layout of lanes are shown in Figure 13.

To evaluate the accuracy of simulation results, the actual average hourly traffic volumes of March 2009 were used as an input of the established random vehicle model. Meanwhile, cable force monitoring data for the same period were extracted and separated. A comparison for the calculated result and the monitoring data of cable NJ21 was conducted during the period from 11:00 to 12:00 on March 6, 2009, as shown in Figure 14. The time history of simulated vehicleinduced cable forces matched well with the monitoring data in normal operation condition. The specific values for comparison are shown in Table 2. In terms of maximum, minimum, and average values, the ratios of calculated result to monitoring data were $0.964,0.881$, and 1.036 , respectively. The simulation results were proved to be in line with the actual situation. The slight deviation may be caused by the neglected wind effect, which will be considered in further research.

Moreover, the Kullback-Leibler (KL) divergence was introduced to quantitatively evaluate the simulation. The calculated KL divergence should be a positive value, and the more its value is close to zero, the more accurate the simulation method used is. Assuming that $P$ and $Q$ are two random variable series, the KL divergence can be expressed as

$$
D_{k l}(P \| Q)=\int_{-\infty}^{+\infty} p(x) \ln \frac{p(x)}{q(x)} \mathrm{d} x,
$$

where $p(x)$ and $q(x)$ are probability density functions of $P$ and $Q$. The KL divergence between the calculated cable forces with the monitoring cable forces was calculated based on equation (10), which resulted to be 0.1219 . The analysis of simulated and actual vehicle-induced cable forces shows that the developed random vehicle model was reliable for simulating response in a specific operational condition when the available records were limited.

The average daily traffic of the third Nanjing Yangtze River Bridge in the analysis period was about 27,000. To predict the extreme value of vehicle-induced responses, prospective traffic volume should be analyzed. In this respect, influencing factors including population, industry, and business development need to be considered. In this study, the traffic volume of another long-span bridge (Jiangyin Bridge) located at Yangtze River near the case bridge was investigated to analyze prospective traffic, for the operational situation of this bridge was close to the saturation level. The average daily traffic of Jiangyin Bridge was about 70,000 vehicles, while its ADTT (average daily truck traffic) was about 11,000 . The traffic jam occurs in Jiangyin Bridge when the daily traffic exceeded 90,000. When the daily traffic volume reached the peak value of 130,000 vehicles on a holiday, a severe traffic jam happened. Mean while, the corresponding ADTT was only 5,000 in the same period. This traffic condition was almost the operational limitation of Jiangyin Bridge. Since ADTT is an important parameter that influences the vehicle-induced cable force, the passenger cars dominating traffic volume are not suitable to calculate response extreme value. As these two bridges are located in adjacent regions of the middle-lower Yangtze plains, the traffic data of Jiangyin Bridge was used as a sample to determine the prospective average daily traffic volume of the third Nanjing Yangtze River Bridge. The result was estimated to be 80,000 with the ADTT of 15,000 .

Then, the received prospective traffic volume was taken as an input parameter of random vehicle model to calculate prospective vehicle-induced responses of cable NJ21. In order to consider various adverse conditions that may appear in service periods, vehicle-induced daily maximum 
TABLE 1: Vehicle types and associated information.

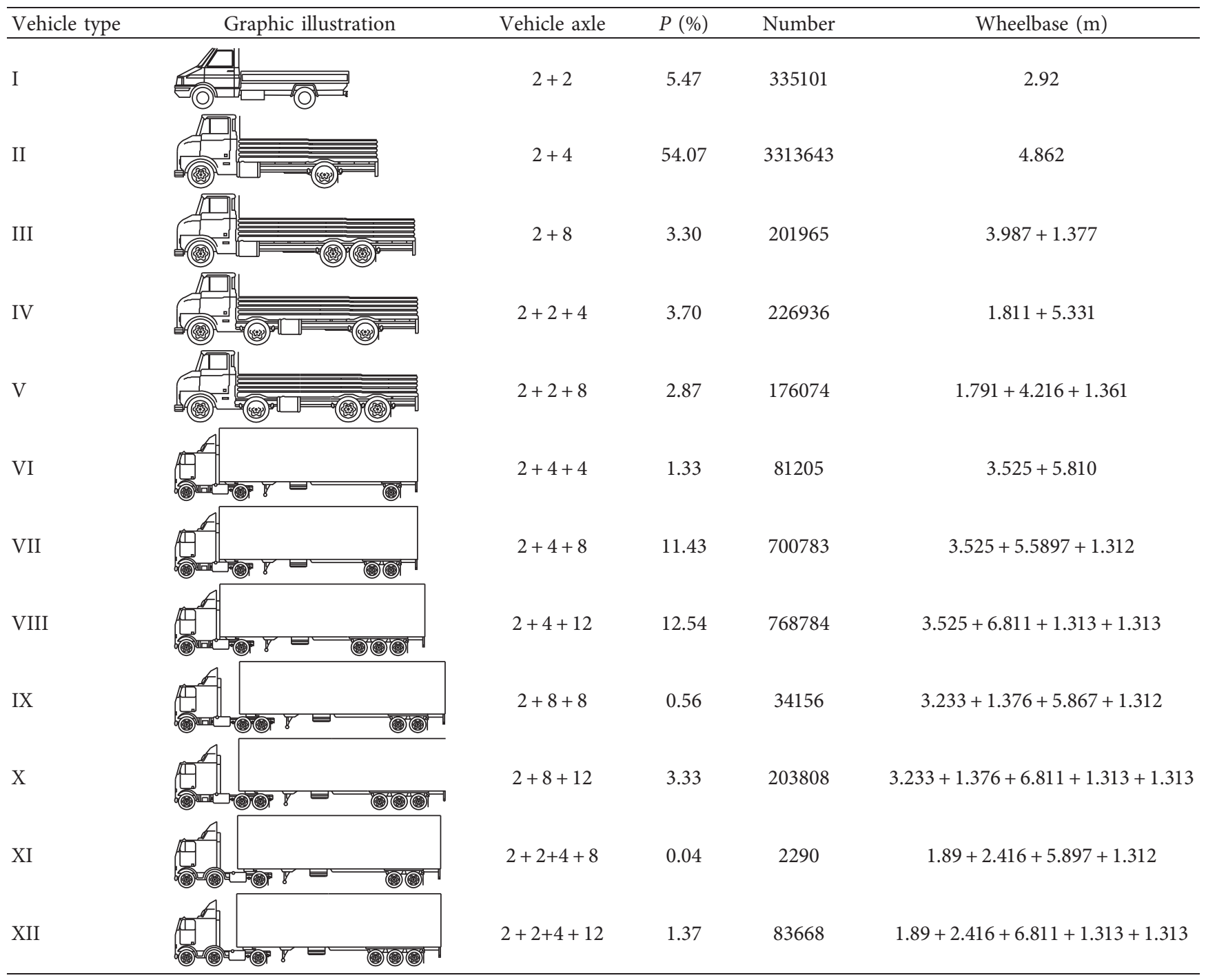

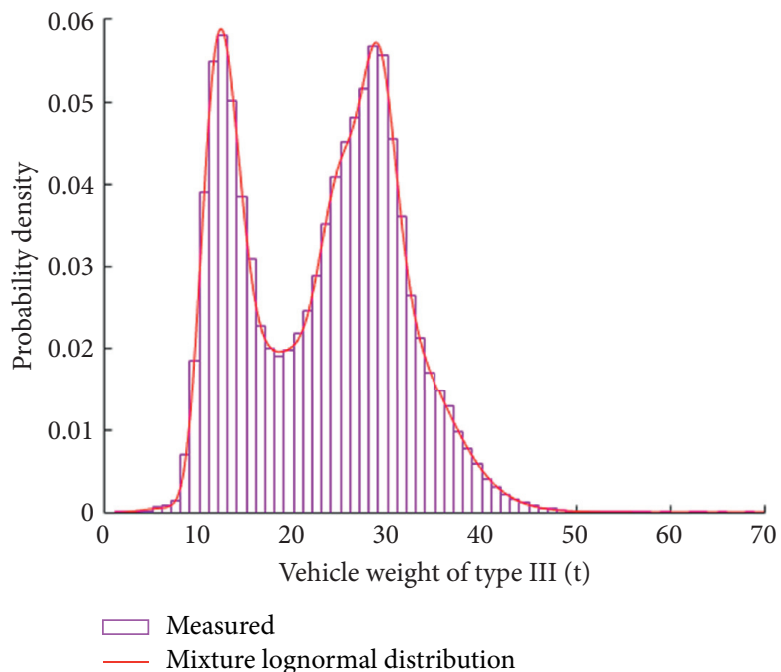

(a)

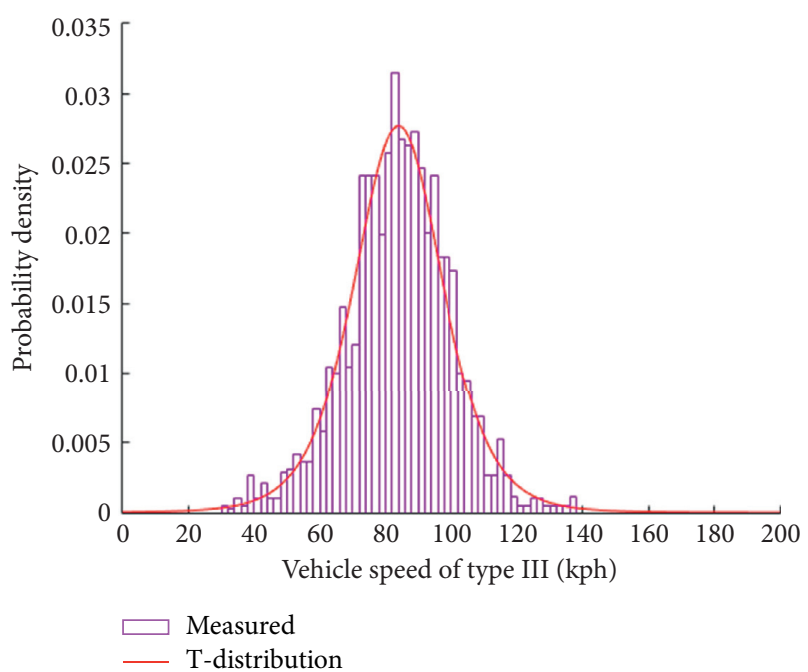

(b)

Figure 12: Continued. 


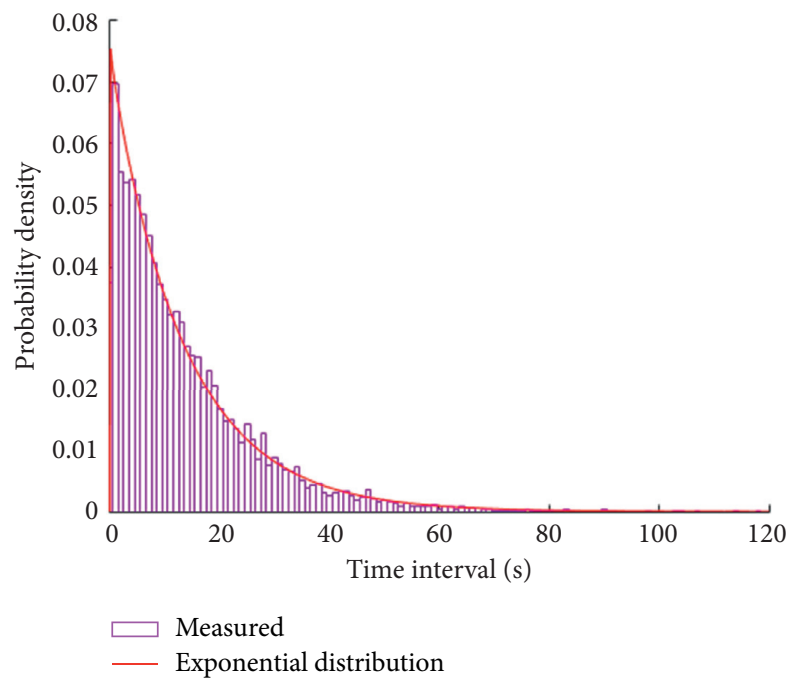

(c)

FIgURE 12: Examples of statistical models: (a) vehicle weight for type III; (b) vehicle speed for type III; (c) the time interval.

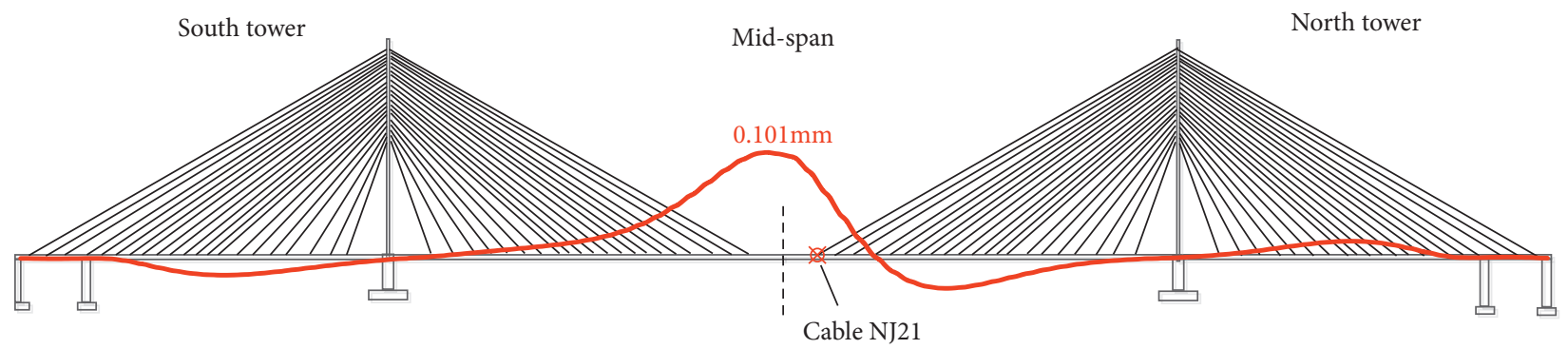

(a)

Downstream

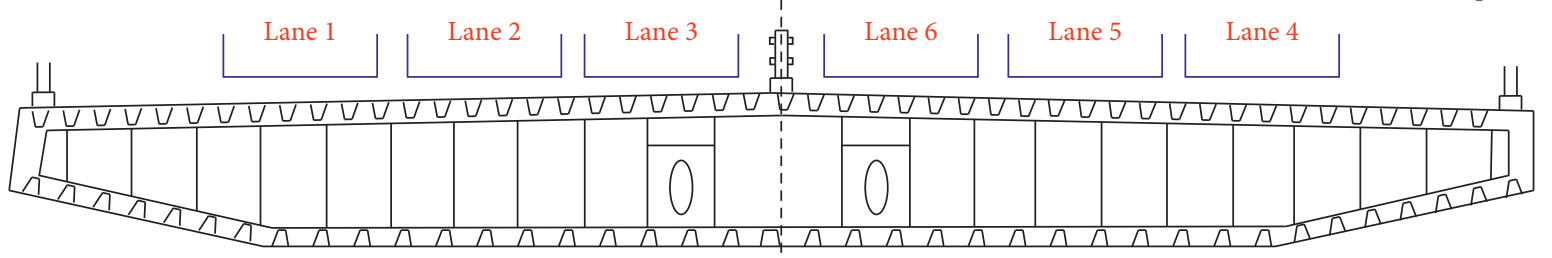

(b)

FIgURE 13: The random vehicle loading procedure: (a) cable force influence line for NJ21; (b) layout of lanes.

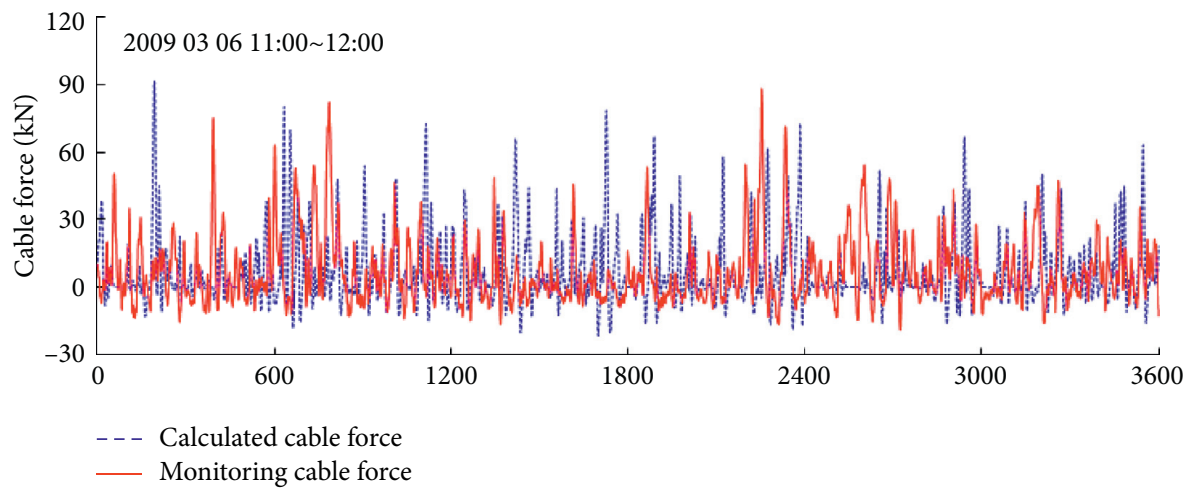

FIGURE 14: The comparison of simulation and monitoring data. 
TABLE 2: Comparison of calculated cables forces with monitoring cable forces.

\begin{tabular}{lccc}
\hline & Maximum value & Minimum value & Average value \\
\hline Calculated cable force $(\mathrm{kN})$ & 91.6294 & -21.6761 & 6.7399 \\
Monitoring data $(\mathrm{kN})$ & 88.3274 & -19.0815 & 6.5012 \\
\hline
\end{tabular}

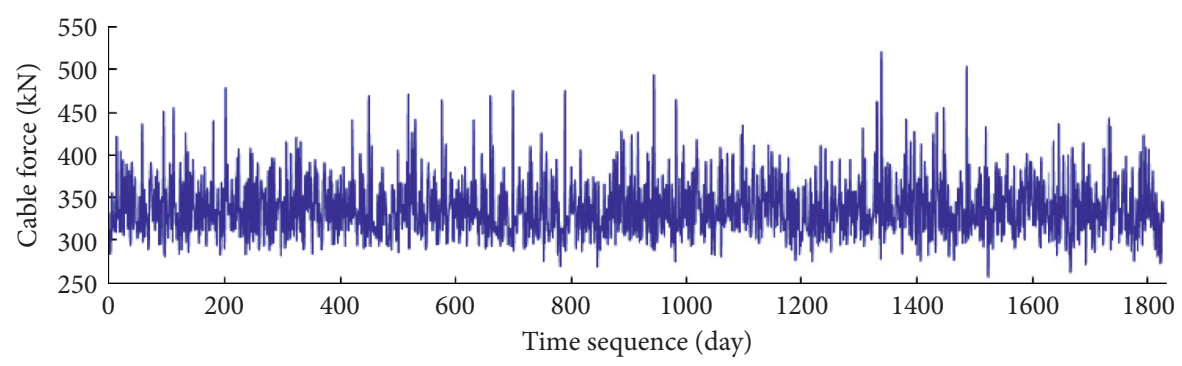

Figure 15: Five-year vehicle-induced daily simulated maximum cable forces.

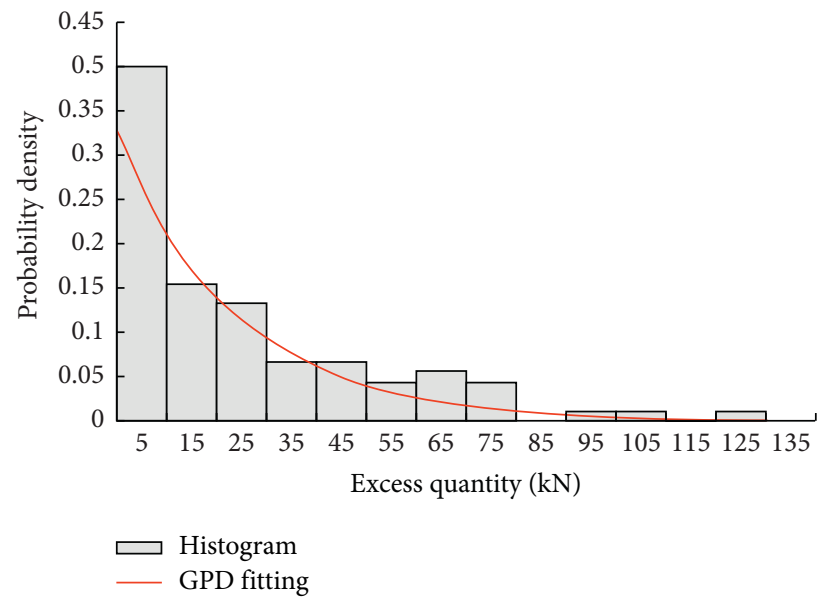

FIgURE 16: The PDF of the GPD for cable force excess quantity.

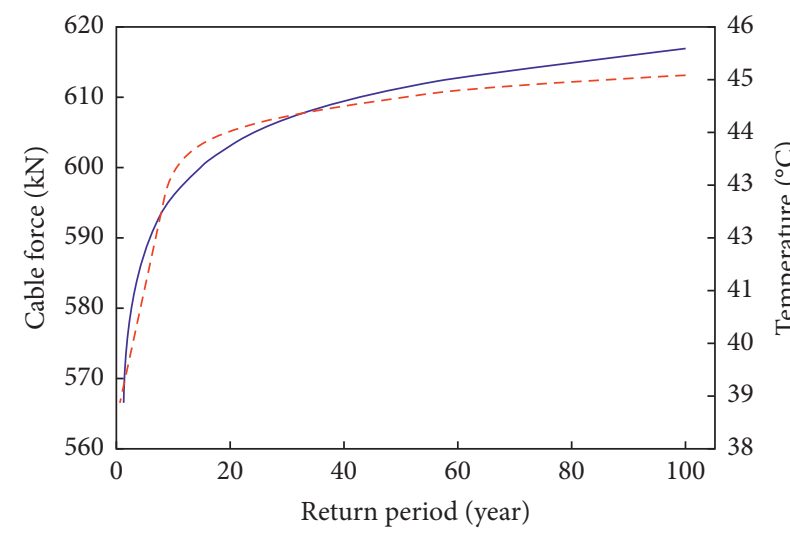

Vehicle-induced response Temperature

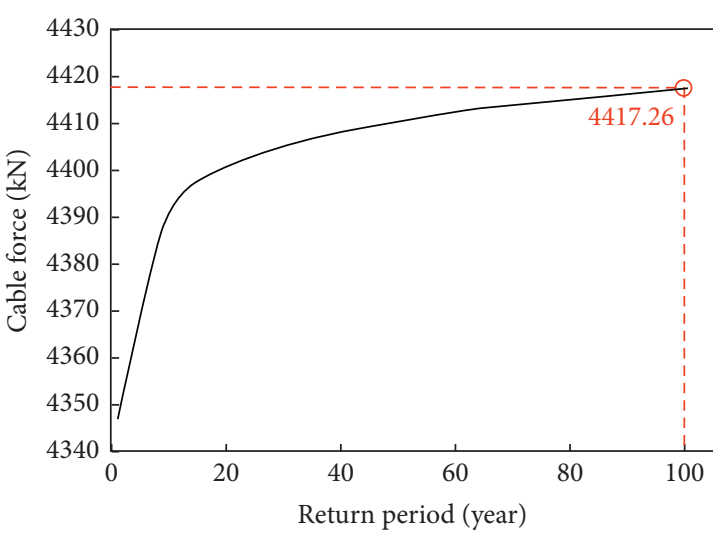

_ Cable force

(a)

(b)

FIGURE 17: Variation of the predicted extreme value with return periods: (a) the vehicle-induced response for NJ21 and temperature; (b) the total cable force. 
cable force of cable NJ21 was simulated for a long period of five years; see Figure 15. With a determined threshold $u_{n}=400 \mathrm{kN}$ and $r=3$, the GPD extreme value analysis was conducted via MATLAB platform. Thus, the shape parameter and the scale parameter can be obtained as $\widehat{\xi}=0.0467$ and $\widehat{\sigma}=24.1651$, respectively. The PDF results from the GPD fitting are shown in Figure 16.

The values of the two parameters of the GPD were substituted into equation (8) to calculate the extreme value of vehicle-induced cable force $F_{\text {Lev }}$ with the return period of 100 years, and the result was obtained as $616.86 \mathrm{kN}$. According to the current Chinese design codes (JTG D602015), the design value of the vehicle-induced cable force was $626.10 \mathrm{kN}$ in Highway-I vehicle load. It indicates that, in operational condition of prospective traffic volume, the extreme value of vehicle-induced cable force with the return period of 100 years was still lower than the design value.

3.4. Estimation Results. To illustrate the predicted extreme value of cable forces in prospective operational conditions, Figure 17 plots the variation of the predicted extreme values of temperature, vehicle induced responses, and total responses with respect to the return period obtained using the proposed methods.

The extreme value of total cable force in prospective operational conditions with the return period of 100 years can be calculated by equation (2); namely, $F_{\mathrm{Tev}}+F_{\mathrm{Lev}}=4417.26 \mathrm{kN}$. As for two ingredients of cable force, only a small percentage of responses were induced by vehicle (616.86 kN and $13.96 \%)$. The corresponding extreme stress of wires was $476.25 \mathrm{MPa}$, which was less than the limitation of $668 \mathrm{MPa}$, calculated from the Chinese design code. The estimation result shows that the longest cable NJ21 of the third Nanjing Yangtze River Bridge will be in a safe status without considering the material degradation. However, it should be mentioned that when more monitoring data becomes available in the future, it needs to be included to update the prediction in order to reduce the uncertainties of parameters. The method can also provide reliable estimates for the cable forces in specific return periods.

\section{Conclusions}

This paper proposed a practical approach to analyze and predict the performance of stay cables of long-span cablestayed bridges based on cable force monitoring data and traffic data. After raw data preprocessing, a random vehicle model was developed and applied to predict the prospective cable force with extreme value theory. To validate the reliability of the proposed method, measurements from the SHM system and the weighing system of the third Nanjing Yangtze River Bridge were involved for a case study. According to the results of the study, the following conclusions can be drawn:

(1) The cable forces for a cable-stayed bridge are considered as the combination of different action effects. The wavelet transform method is suitable to separate the monitoring cable force induced by different effects.

(2) The multiparameter vehicle modelling method was developed to generate Monte Carlo random traffic flow based on the collected bridge weighing system data and then calculated vehicle-induced response. The vehicles can be divided into specific several types according to the numbers of axles and wheels.

(3) As a supplement to the normal distribution, the GPD-based extreme value method was utilized to predict extreme cable force in a specific return period. In the application, the estimated extreme cable force in prospective operational conditions with the return period of 100 years was $4239.04 \mathrm{kN}$.

(4) The proposed analysis and estimation methods were applied to the third Nanjing Yangtze River Bridge. Based on the actual cable force monitoring data and the bridge weighing system data, the extreme cable force in prospective traffic operational condition for cable NJ21 was obtained. The method provided reliable estimates for the cable forces in specific return periods with limited data.

\section{Data Availability}

The data used to support the findings of this study are available from the corresponding author upon request.

\section{Conflicts of Interest}

The authors declare that there are no conflicts of interest regarding the publication of this paper.

\section{Acknowledgments}

The research was supported by the Natural Science Foundation of Jiangsu Province (no. BK20181278), Transportation Science Research Project in Jiangsu (no. 2019Z02), the Postgraduate Research \& Practice Innovation Program of Jiangsu Province (no. KYCX19_0099), and the Academician Special Science Research Project of CCCC (no. YSZX-03-202001-B).

\section{References}

[1] A. B. Mehrabi, "Performance of cable-stayed bridges: evaluation methods, observations, and a rehabilitation case," Journal of Performance of Constructed Facilities, vol. 30, no. 1, Article ID C4014007, 2016.

[2] C. Jiang, J. Lu, Y. Jiang, X. Cai, and C. Peng, "Analysis on characteristics of traffic demand about Sutong Bridge," Procedia Social \& Behavioral Sciences, vol. 96, pp. 2553-2562, 2013.

[3] N. Lu, Y. Ma, and Y. Liu, "Evaluating probabilistic traffic load effects on large bridges using long-term traffic monitoring data," Sensors, vol. 19, Article ID 5056, 2019.

[4] C. Leahy, E. OBrien, and A. O'Connor, "The effect of traffic growth on characteristic bridge load effects," Transportation Research Procedia, vol. 14, pp. 3990-3999, 2016. 
[5] N. Lu, M. Beer, M. Noori, and Y. Liu, "Lifetime deflections of long-span bridges under dynamic and growing traffic loads," Journal of Bridge Engineering, vol. 22, Article ID 04017086, 2017.

[6] X. Xu, Y. Ren, Q. Huang et al., "Anomaly detection for large span bridges during operational phase using structural health monitoring data," Smart Materials and Structures, vol. 29, Article ID 045029, 2020.

[7] Y. Cheng, J. Zhang, and J. Wu, "Fragility analysis of a selfanchored suspension bridge based on structural health monitoring data," Advances in Civil Engineering, vol. 2019, Article ID 7467920, 19 pages, 2019.

[8] A. D. Orcesi and D. M. Frangopol, "Bridge performance monitoring based on traffic data," Journal of Engineering Mechanics, vol. 139, no. 11, pp. 1508-1520, 2013.

[9] Y. Fujino and D. M. Siringoringo, "Bridge monitoring in Japan: the needs and strategies," Structure and Infrastructure Engineering, vol. 7, no. 7-8, pp. 597-611, 2011.

[10] S. Kim and D. M. Frangopol, "Optimal planning of structural performance monitoring based on reliability importance assessment," Probabilistic Engineering Mechanics, vol. 25, no. 1, pp. 86-98, 2010.

[11] A. D. Ocresi and D. M. Frangopol, "Optimization of bridge maintenance strategies based on structural health monitoring information," Structural Safety, vol. 33, pp. 26-41, 2011.

[12] A. D. Ocresi and D. M. Frangopol, "Bridge performance monitoring based on traffic data," Journal of Engineering Mechanics, vol. 139, no. 11, pp. 1508-1520, 2013.

[13] B. Atmaca, T. Dede, and M. Grzywinski, "Optimization of cables size and prestressing force for a single pylon cablestayed bridge with Jaya algorithm," Steel and Composite Structures, vol. 34, no. 6, pp. 853-862, 2020.

[14] P. Asadollahi, Y. Huang, and J. Li, "Bayesian finite element model updating and assessment of cable-stayed bridges using wireless sensor data," Sensors, vol. 18, Article ID 3057, 2018.

[15] H. Lu, J. Hao, J. Zhong, Y. Wang, and H. Yang, "Analysis of sunshine temperature field of steel box girder based on monitoring data," Advances in Civil Engineering, vol. 2020, Article ID 9572602, 10 pages, 2020.

[16] J. F. Wang, J. T. Zhang, R. Q. Xu, and Z. X. Yang, "Evaluation of thermal effects on cable forces of a long-span prestressed concrete cable stayed bridge," Journal of Performance of Constructed Facilities, vol. 33, no. 6, Article ID 04019072, 2019.

[17] R. Kromanis and P. Kripakaran, "Predicting thermal response of bridges using regression models derived from measurement histories," Computers \& Structures, vol. 136, pp. 64-77, 2014.

[18] Y. J. Zhu, Y. Q. Ni, A. Jesus, J. L. Liu, and I. Laory, “Thermal strain extraction methodologies for bridge structural condition assessment," Smart Materials and Structures, vol. 27, no. 10, Article ID 105051, 2018.

[19] X. Xu, Y. Ren, Q. Huang, D.-Y. Zhao, Z.-J. Tong, and W.-J. Chang, "Thermal response separation for bridge long-term monitoring systems using multi-resolution wavelet-based methodologies," Journal of Civil Structural Health Monitoring, vol. 10, no. 3, pp. 527-541, 2020.

[20] X. Xu, Q. Huang, Y. Ren, D.-Y. Zhao, J. Yang, and D.-Y. Zhang, "Modeling and separation of thermal effects from cable-stayed bridge response," Journal of Bridge Engineering, vol. 24, no. 5, Article ID 04019028, 2019.

[21] R. Kromanis and P. Kripakaran, "Data-driven approaches for measurement interpretation: analysing integrated thermal and vehicular response in bridge structural health monitoring," Advanced Engineering Informatics, vol. 34, pp. 46-59, 2017.

[22] Y. Zhou and L. Sun, "A comprehensive study of the thermal response of a long-span cable-stayed bridge: from monitoring phenomena to underlying mechanisms," Mechanical Systems and Signal Processing, vol. 124, pp. 330-348, 2019.

[23] P. Kotsovinos, A. Atalioti, N. McSwiney, F. Lugaresi, G. Rein, and A. J. Sadowski, "Analysis of the thermomechanical response of structural cables subject to fire," Fire Technology, vol. 56, no. 2, pp. 515-543, 2020.

[24] Z. Liu, Q. Huang, Y. Shan, J. Chen, H. Cao, and Z. Yu, "Quantifying high temperature-induced breakage instant of prestressing high-strength steel wire," Journal of Materials in Civil Engineering, vol. 32, no. 7, Article ID 04020189, 2020.

[25] Y. Zhou, Y. Pei, Z. Li, L. Fang, Y. Zhao, and W. Yi, "Vehicle weight identification system for spatiotemporal load distribution on bridges based on non-contact machine vision technology and deep learning algorithms," Measurement, vol. 159, Article ID 107801, 2020.

[26] J. Gajda, R. Sroka, and P. Burnos, "Sensor data fusion in multisensor weigh-in-motion Systems," Sensors, vol. 20, Article ID 3357, 2020.

[27] R. Ma, S. Xu, D. Wang, and A. Chen, "Vehicle models for fatigue loading on steel box-girder bridges based on weigh-inmotion data," Structure and Infrastructure Engineering, vol. 14, no. 6, pp. 701-713, 2018.

[28] Y. Wang, G. Zongyu, Z. Wang, and J. Yang, "A case study of traffic load for long-span suspension bridges," Structural Engineering International, vol. 24, no. 3, pp. 352-360, 2014.

[29] J. Zhou, X. Ruan, X. Shi, and C. C. Caprani, "An efficient approach for traffic load modelling of long span bridges," Structure and Infrastructure Engineering, vol. 15, no. 5, pp. 569-581, 2019.

[30] T. Guo, D. M. Frangopol, and Y. Chen, "Fatigue reliability assessment of steel bridge details integrating weigh-in-motion data and probabilistic finite element analysis," Computers \& Structures, vol. 112-113, pp. 245-257, 2012.

[31] F.-Y. Wang and Y.-L. Xu, "Traffic load simulation for longspan suspension bridges," Journal of Bridge Engineering, vol. 24, no. 5, Article ID 05019005, 2019.

[32] Y. Liu, Y. Deng, and C. S. Cai, "Deflection monitoring and assessment for a suspension bridge using a connected pipe system: a case study in China," Structural Control and Health Monitoring, vol. 22, no. 12, pp. 1408-1425, 2015.

[33] E. J. OBrien, A. Bordallo-Ruiz, and B. Enright, "Lifetime maximum load effects on short-span bridges subject to growing traffic volumes," Structural Safety, vol. 50, pp. 113122,2014

[34] Z. W. Chen, Y. L. Xu, Y. Xia, Q. Li, and K. Y. Wong, "Fatigue analysis of long-span suspension bridges under multiple loading: case study," Engineering Structures, vol. 33, no. 12, pp. 3246-3256, 2011.

[35] C. Jiang, C. Wu, C. S. Cai, and W. Xiong, "Fatigue analysis of stay cables on the long-span bridges under combined action of traffic and wind," Engineering Structures, vol. 207, Article ID 110212, 2020.

[36] B. Atmaca, "Determination of minimum depth of prestressed concrete I-Girder bridge for different design truck," Computers and Concrete, vol. 24, no. 4, pp. 303-311, 2019.

[37] Y. Zhou and S. Chen, "Dynamic simulation of a long-span bridge-traffic system subjected to combined service and extreme loads," Journal of Structural Engineering, vol. 141, no. 9, Article ID 04014215, 2015. 
[38] C. Cremona, "Optimal extrapolation of traffic load effects," Structural Safety, vol. 23, no. 1, pp. 31-46, 2001.

[39] M. Grigoriu, "Estimates of extreme winds from short records," Journal of Structural Engineering, vol. 110, no. 7, pp. 1467-1484, 1984.

[40] Q. J. Wang, "The POT model described by the generalized Pareto distribution with Poisson arrival rate," Journal of Hydrology, vol. 129, no. 1-4, pp. 263-280, 1991.

[41] E. Castillo and A. S. Hadi, "Fitting the generalized Pareto distribution to data," Journal of the American Statistical Association, vol. 92, no. 440, pp. 1609-1620, 1997.

[42] Y. Ren, X. Xu, Q. Huang, D.-Y. Zhao, and J. Yang, "Long-term condition evaluation for stay cable systems using dead loadinduced cable forces," Advances in Structural Engineering, vol. 22, no. 7, pp. 1644-1656, 2019.

[43] Z.-Y. Fan, Q. Huang, Y. Ren, Z.-Y. Zhu, and X. Xu, "A cointegration approach for cable anomaly warning based on structural health monitoring data: an application to cablestayed bridges," Advances in Structural Engineering, vol. 23, no. 13, pp. 2789-2802, Article ID 1369433220924793, 2020. 